\title{
Illusionary finance and trading behavior
}

M. Hamadi, E. Rengifo and D. Salzman

Discussion Paper 2005-12

Département des Sciences Économiques

de l'Université catholique de Louvain 


\title{
Illusionary Finance and Trading Behavior*
}

\author{
Malika Hamadi $^{\S} \quad$ Erick Rengifo ${ }^{* *} \quad$ Diego Salzman $^{\dagger \dagger}$
}

First draft: September 2004

This draft: January 2005

\begin{abstract}
One important aspect of financial markets is that there might be some traders that intentionally mislead other market participants by creating illusions in order to obtain a profit. We call this new concept illusionary finance. We present an analysis of how illusions can be created and disseminated in financial markets based on certain psychological principles that explain agents' decisions under time pressure and polysemous signals. We develop a simple model that incorporates the illusions in the price formation process. Furthermore, using powerful simulations, we show how illusions can be incorporated, directly or indirectly, in the expected prices of the traders.
\end{abstract}

Keywords: Illusionary Finance, Behavioral Finance, Evolutionary Finance, Neuroeconomics.

JEL Classification: C32, C35, G10

\footnotetext{
${ }^{*}$ The authors would like to thank Luc Bauwens, Anke Gerber, Andreas Heinen, Peter Malkin, Eric Strobl and Genaro Sucarrat for helpful comments and suggestions. Malika Hamadi is grateful for the financial support from the Belgian French Community's program 'Action de Recherches Concertée' 99/04-235. Diego Salzman acknowledges the financial support provided through the European Community's Human Potential Programme under contract HPRN-CT-2002-00232, MICFINMA.

${ }^{\S}$ Department of Economics, Université catholique de Louvain. E-mail:hamadi@ires.ucl.ac.be

** Center of Operations Research and Econometrics, Université catholique de Louvain. E-mail: rengifo@core.ucl.ac.be

${ }^{\dagger \dagger}$ Corresponding author. Center of Operations Research and Econometrics, Université catholique de Louvain, 34 Voie du Roman Pays, 1348 Louvain-la-Neuve, Belgium, e-mail: salzman@core.ucl.ac.be
} 


\section{Introduction}

The efficient market hypothesis (EMH) suggests that, at any time, prices fully and instantaneously reflect all available relevant information on a particular stock or market (Fama (1970)). The information contained in the prices also reflects the way in which investors perceive and interpret such information. Thus, no investor has an advantage in predicting stock prices since no one has access to information not already available to everyone else. Accordingly, the EMH states that it is impossible to "beat the market" because prices already incorporate and reflect all relevant information. More importantly, the EMH framework assumes the existence of rational agents. This assumption is characterized by two aspects. Firstly, the agents update their beliefs by correctly incorporating all relevant information of the current situation, as well as expectations about the future opportunities and risks. Secondly, they make choices that are normatively acceptable, i.e., consistent with Savage's notion of subjective expected utility. However, in reality people's decisions arguably often express affective evaluation (attitudes) that do not conform to the logic of economic rationality. Moreover, most judgements and most choices are made intuitively. In order to understand other important aspects that influence agents' decisions, one may need to understand some human psychological principles [(Kahneman, Wakker, and Sarin (1997) and Kahneman (2003)).

One area in which researchers have linked psychology with economics is behavioral finance, which provides explanations to well known market anomalies, such as: the stock market overreaction and underreaction (Daniel, Hirshleifer, and Subrahmanyam (1998), Barberis, Shleifer, and Vishny (1998), and DeBondt and Thaler (1985)); the persistence of mispricing (De Long, Shleifer, Summers, and Waldman (1990); Shleifer and Vishny (1997)); the survival of overconfident traders in a competitive stock market (Hirshleifer and Luo (2001)); and the market inefficiencies that allow some individual skilled investors to earn abnormal profits (Coval, Hirshleifer, and Shumway (2002)). The explanation for these market anomalies brought from the psychological field are, for example, prospect theory, representativeness heuristic, conservatism, overconfidence, gambling behavior, and speculation. The behavioral finance literature shows some limits of the efficient market hypothesis when psychological aspects are taken into account. 
In this paper, we introduce the concept of illusionary finance. We present an analysis of how illusions can be created and disseminated in stock markets. Our work is based on certain psychological aspects that explain some agents' decisions under time pressure and polysemous signals which are defined as indicators that have multiple interpretations. ${ }^{1}$

Illusionary finance studies how an agent can profit from other agents psychological biases, taking advantage of polysemous signals and time pressure. Illusionary finance is possible since agents cannot make fully-rational decisions all the time, at least in the economic sense. Instead, they make their decisions based on "bounded rationality" (Kahneman (2003)). The judgements that people express, the actions that they take, and the mistakes that they make depend on the monitoring and corrective functions of reasoning, and on the impressions and tendencies generated by their intuitions.

The rest of the paper is organized as follows: Section 2 presents the psychological bases of illusionary finance. Section 3 introduces the concept of illusionary finance and explain how to distinguish it from noise. Section 4, gives the intuition on the creation of illusions in stocks markets and their influence on the price formation process. Section 5 explains the simulation results and finally and Section 6 concludes and provides an outlook for future research.

\section{Psychological foundations of illusionary finance}

In this section we introduce the concept of illusions that are important psychological features, which might influence agents' decisions. The word illusion comes from the Latin "illusio," which means the action of mocking, deceiving, the state or fact of being intellectually deceived or misled, something that deceives or misleads intellectually, or the perception of something objectively existing in such a way as to cause misinterpretation of its actual nature. ${ }^{2}$ Agents can be subject to illusions; that is, agents do not experience reality accurately, but instead experience something that appears and feels very real.

The definition we adopt for illusions in financial markets is the perception of something

\footnotetext{
${ }^{1}$ For more information about the semantic concept of information and polysemous signals, please refer to the works of Saussure (1967) and Dretske (1981).

${ }^{2}$ Merriam-Webster dictionary.
} 
objectively existing and created intentionally by someone in such a way that its actual nature is misinterpreted. We call the illusionary trader the one who creates the illusion. An illusionary trader creates an illusion by sending polysemous signals to the market and taking advantages of the other traders psychological biases and time pressure in order to obtain a positive return. The psychological notions that introduce illusionary trading in stock markets are bounded rationality, intuition and reasoning, framing effects, attribute substitution, and prospect theory.

In order to understand the foundations of illusionary finance, we need to understand that as any other economic agent, a trader in a stock market face cognitive processes like those presented in Kahneman and Frederick (2002). Furthermore, they are confronted by time pressure and polysemous signals when making their decisions; they must decide in a very short period of time which information is important and incorporate it in their information set in order to form their expectations. Based on Kahneman and Frederick (2002), we present in the following some cognitive processes and their influence on traders' decisions.

Cognitive processes can be divided into two families: intuition and reasoning. ${ }^{3}$ Intuition is a process that is spontaneous, effortless, and fast. Reasoning is deliberate, rule-governed, effortful, and slow. Usually, the relevant characteristic to differentiate between both systems is the effort and the time used by the agent. We can imagine easily that a trader is subject to these cognitive processes (intuition and reasoning) when he takes his decisions.

Although intuition is present in most of our judgements and choices, it is normally monitored by reasoning (system 2). However, this monitoring is lax; many judgements and choices are expressed even if some of them are erroneous. Intuition (system 1) can deal with stored concepts and precepts and can be evoked by language. Intuition comes to mind very fast in the form of percepts. The ease with which mental contents come to mind is known as accessibility. Some attributes are more accessible than others. Attributes that are routinely and automatically produced by the perceptual system ${ }^{4}$ or by intuition have been

\footnotetext{
${ }^{3}$ According to the labels given by Stanovich and West (2000), intuition is known as system 1 and reasoning as system 2 .

${ }^{4}$ Perception is the awareness that comes from the stimuli of the physical world, the sensation of it and our experience in interpreting it. Perception is the basic way of knowing reality. But although perception seem accurate, it is often subject to weaknesses and limits, Cobb (1999).
} 
called natural assessments, such as similarity, causal propensity, surprisingness, affective valence, and mood. Some determinants of accessibility are probably genetic, but others are developed through experience. The acquisition of skill gradually increases the accessibility of useful responses and of productive ways to organize information. Skills are acquired by long exercises, but once they are obtained they come to the mind rapidly and effortlessly. Thus, the cognitive system has two ways of adjusting to changes: a short-term process that is flexible and effortless, and a long-term process of skill acquisition that eventually produces highly effective responses at low cost. As stated by Kahneman, some of the most highly skilled cognitive activities are intuitive, but the intuition is prone to systematic biases and errors that are sometimes not corrected at all and are rarely corrected perfectly.

An important factor that influences the agents' judgements and decisions given by their intuitions is the framing effect. The framing effect refers to problems that can be equivalently described in many different ways leading to different choices simply by altering the relative salience of different aspects of them. The different representations of the outcomes highlight some features of the situation and mask others. Agents (i.e. traders) can react differently depending on the highlighted and masked features. Furthermore, Tversky and Kahneman (1974) argue that "people rely on a limited number of heuristic principles which reduce the complex tasks of assessing probabilities and predicting values to simple judgements operations; ${ }^{5}$ in general, these heuristics are quite useful, but sometimes they lead to severe and systematic errors."

Due to time pressure and time available for deliberation, people's ability to avoid errors of intuitive judgement is impaired (Finucane, A., Slovic, and Johnson (2000)). This is true for traders who need to take decisions on spot. For example, their ability is impaired by concurrent involvement in several different cognitive tasks if the agent is mentally occupied by a demanding mental activity (Gilbert(1989, 1991, 2002)); by performing the task in the evening for "morning people" and in the morning for "evening people" (Bodenhausen (1990)); and surprisingly, by being in a good mood (Isen, Nygren, and Ashby (1988)).

\footnotetext{
${ }^{5}$ This is related to the concept of attribute substitution from Kahneman and Frederick (2002): "a judgement is said to be mediated by a heuristic when the individual assesses a specified target attribute of a judgement object by substituting another property of that object (the heuristic attribute) which comes more readily to mind." This means that agents confronted with a difficult question often answer an easier one instead, usually without being aware of the substitution.
} 
Conversely, the facility of reasoning is positively correlated with exposure to statistical thinking (Nisbett, Krantz, Jepson, and Kunda (1983), Agnoli and Krantz (1989) and Agnoli (1991)) and with intelligence (Stanovich and West (2000)), a trait that psychologists have labeled "need for cognition" (which is roughly whether people find thinking fun) (Shafir and LeBoeuf (2002)).

In summary, agents do not make fully-rational decisions, at least in the economic sense. Instead, their decisions are based on "bounded rationality". ${ }^{6}$ Kahneman (2003) refers to bounded rationality as different geographic maps of the same territory. With respect to these boundaries of intuitive thinking, the judgements that people express, the actions that they take, and the mistakes that they commit depend on the monitoring and corrective functions of our reason (system 2) as well as on the impressions and tendencies generated by our intuition (system 1 ).

Kahneman and Tversky (1979) point out that agents' perceptions are reference-dependent; the perceived attributes of a focal stimulus reflect the contrast between that stimulus and the context of prior and concurrent stimuli. The standard economic theory assumes that the analysis of the utility of decision outcomes is determined entirely by the final wealth, and it is therefore reference-independent. Based on experimentation, Kahneman and Tversky (1979) concluded that people tend to change abruptly from risk-aversion to risk-seeking accordingly to how the problem is presented. This feature could not be explained by a utility function for wealth as preferences appear to be determined by attitudes to gains and losses defined relatively to a reference point. That is, they suggest an alternative theory of risk in which the carriers of utility are gains and losses (changes of wealth rather than states of wealth). This new theory is called prospect theory. The distinctive predictions of prospect theory follow from the shape of the value function defined on gains and losses. The value function is characterized by three features: (1) it is concave in the domain of gains, favoring risk aversion; (2) it is convex in the domain of losses, favoring risk-seeking; and (3) the function is sharply kinked at the reference point and loss-averse (steeper for losses than for gains by a factor of about 2-2.5 (Kahneman (1991) and Tversky and Kahneman (1992)). The activity of traders in stock markets fits the predictions of prospect theory very

\footnotetext{
${ }^{6}$ The notion of bounded rationality goes back to Simon (1957).
} 
well. Traders are much more interested in short term realizations rather than final wealth.

Prospect theory is concerned with immediate outcomes, in contrast with utility theory, which defines outcomes as states or as changes with only future consequences. The value function of prospect theory presumably reflects an anticipation of the valence and intensity of the emotion that will be experienced at moments of transition from one state to another (Kahneman (2000a), Kahneman (2000b) and Mellers (2000)).

\section{Illusionary finance}

In this section, we show how illusionary finance tricks financial markets. The psychological aspects discussed in section 2 allow us to introduce the illusionary mechanism that can be created in the stock market and embedded in the information set as if it were relevant information and not an illusion. This illusionary mechanism is related to behavioral finance given that in behavioral finance literature, market anomalies are extensively reported. Coval, Hirshleifer, and Shumway (2002) examine the fact that there are individual investors capable of beating the market, which implies the violation of the semi-strong form market efficiency. They conclude by an interesting question: are the large brokerage companies aware of the value of the information contained in their customers' trades? In our framework, the fact that there are agents that are not aware of the relevance of the information contained in trades means that it is possible to integrate an illusion into the agents' information set.

It is also important to clarify how the illusionary trader takes advantage of the psychological bias of the other market participants. ${ }^{7}$ Firstly, he sends a polysemous signal with the intention to create a financial illusion for the other market participants. Secondly, this sign is perceived by other traders. According to the perception of the signal, the type of trader (information trader, noise $\operatorname{trader}^{8}$ ), and the external circumstances (bearish or bullish market) including the time constraint to make decisions, the signal might be considered as information or noise. Following Thaler (1993) and Black (1986), we can define

\footnotetext{
${ }^{7}$ Illusionary traders differ from speculators since speculators are those traders that profit from information they have about future prices (Harris (2003)), illusionary traders create illusions by sending polysemous signals.

${ }^{8}$ As in Black (1986).
} 
noise as the opposite of news. Information traders trade on the basis of news (facts, forecasts, etc.). Noise traders trade randomly and not based on information. ${ }^{9}$ Even though the information sets of the information traders and the noise traders are different, information traders might consider the illusion as noise or as information. If they consider the illusion simply as noise, they do not use it in their information set and the illusion has no effect. On the other hand, if they consider this illusion as information, they consider it in their information set. We call this sub-group of traders believers.

The desired impact of the illusion depends on many factors that the illusionary trader cannot control but that he can use when the opportunity shows up. The reason why information traders trade on illusions is simple: they consider the perceived illusion not as noise but as information. This is possible in stock markets because there is so much noise in the market that they do not know if they are trading on noise or on information, and when deciding about what is information, they can make mistakes. The illusionary trader takes advantage of this situation to incorporate the illusion in the information set of certain traders with the clear objective of profiting from this situation. The fact that believers take into account illusions may not be completely irrational. Even if they figure out that some information is indeed an illusion, it may nevertheless be rational to take the illusion into account, as long as they believe that there are other believers in the market who take the illusion into account. If no one takes the illusion into account and everyone rationally anticipates that, then it is a best reply not to take it into account. However, if everyone takes the illusion into account and again everyone rationally anticipates that, then it is a best reply to take it into account.

Black (1986) presents a paper describing and explaining what noise is in stock markets. He describes an information trader as someone who has the information or insights on individual firms and a noise trader as someone that trades on something else. Black (1986) argues that noise makes financial markets possible, but also makes them imperfect. In this paper, we add a new type of traders into financial markets called illusionary traders. These traders send polysemous signals to the market and expect to profit from this information.

According to Black (1986), information traders take advantage from their positions in

\footnotetext{
${ }^{9}$ For example they trade to match their own liquidity requirements because of inherited money or because they want to buy a new car or house.
} 
trading with noise traders because they have some relevant information about individual firms. With a lot of noise the information traders are more profitable, simply because prices have more noise in them. However, the information traders can never be sure that they are trading on information rather than noise. They can always think that the information they have received has already been reflected in prices, and then trading on this kind of information will be just like trading on noise. When traders face a lot of information arriving at the market, as long as we are talking about potentially relevant information, the problem is that there are many possibilities to be ruled out before they can be sure to have determined which information is relevant. In short, the more possibilities of potential relevant information, the harder it is to find out what is relevant, and this fact can be used by illusionary traders.

In Black (1986), the prices in the market reflect both the information that the information traders trade on and the noise that noise traders trade on. In the illusionary finance context, we add to this price formation setup the illusion that the believers trade on.

Illusionary traders add misleading signals (illusions) to take advantage from the traders that we call believers. The group of believers can be either information traders or noise traders.

One should note that Black (1986) did not consider traders that trade on illusions; he only considered the noise traders explaining that noise traders are necessary for financial markets to be operative. Illusionary traders are not necessary, but they may exist. Moreover, recent financial frenzies and scandals cannot be the result of only noise. Our contribution is to introduce the concept of illusionary finance, which we think is more realistic than considering only noise.

\section{Simulations}

In this paper our intention is to show using simulation techniques that it is possible to create illusions that translate into positive returns. We argue that illusions imply superior information for the traders who create them because they are the only ones that know about them. These traders use this superior information for their own interest. We do not 
present a theoretical model of illusions. This and some other ideas presented hereafter are left as open questions for future research. What we intend with this simulation is to show the possibility of the existence of illusions in market-maker markets such as the New York Stock Exchange (NYSE). We develop a simulation for a single asset that is as random and as little model controlled as possible.

The market-maker markets present the following features of intra-daily trading, that go along with the ideas presented before:

- The speed of the transactions and the dissemination of information is fast, hence traders are under big time pressure.

- There are polysemous signals arriving to the market and traders might not distinguish between what is relevant, and what is noise and illusion.

- There is a large number of traders.

Following Glosten (1994) we define two kinds of traders interacting in the stocks markets: patient and impatient traders. Impatient traders are the traders who submit market orders (MO) and patient traders submit limit orders (LO). The reasons for submitting MO instead of LO can be due to private information or due to liquidity reasons. In our paper the focus is going to be on the impatient traders and we are going to assume that the book, maintained by the market-maker, is exogenous and spontaneously refilled by the patient traders. We also classify impatient traders into three types: (1) Information traders, who neither believe nor incorporate the illusion in their decision sets. (2) Believers, who believe in the illusion and incorporate it in their expectations about future prices. (3) Noise traders who consider in their expectations "relevant" and "irrelevant" information without distinguishing between them.

We define $N_{t}$ as the proportion of impatient traders at time $t$ (number of impatient traders/total number of traders), and $M_{t}$ the proportion of patient traders at time $t$ (number of patient traders/total number of traders). ${ }^{10}$ Thus, $N_{t}+M_{t}=1$.

We assume that each trader can make a single trade each period, hence one trader equal one trade.

\footnotetext{
${ }^{10} \mathrm{We}$ assume that there is a given fixed number of traders during the whole simulation exercise.
} 
In our simulation we focus on the proportion of impatient traders (information traders, believers and noise traders) which, by assumption, is equal to the number of trades. We assume that the proportion of impatient traders $\left(N_{t}\right)$ is not affected by the illusions. What is affected however, is the proportion of these traders, i.e. some information traders become believers. This is an important assumption in the simulation.

However, special care must be taken with respect to the timing of illusions in the market. An illusion is sent to the market at time $t^{11}$. There are some information traders who do not consider it in their information set; however, in their information set of the next period $(t+1)$, they will consider the prices at time $t$. Since prices at time $t$ already contain the illusion, these information traders are indirectly "believing" in the illusion.

In our framework the information traders (INF) at time $t-1$ forecast the asset price for time $t$ simply as:

$$
E\left[P_{t} \mid \mathcal{F}_{t-1}^{I N F}\right]=\bar{P}_{t}^{I N F}=\frac{1}{n} \sum_{i=1}^{n} P_{t-i}
$$

where $\bar{P}_{t}^{I N F}$ is their expected price at $t$ given their information set $\left(\mathcal{F}_{t-1}^{I N F}\right)$ at $t-1$. The information set at $t-1$ contains only information about past prices. $P_{t-i}$ are past prices. $n$ is the number of past price realizations that are taken into account to determine the expected prices.

We assume that noise traders (NT) simply make random price expectations: ${ }^{12}$

$$
\bar{P}_{t}^{N T}=\varepsilon_{t}
$$

Believers' (B) expected prices are:

$$
E\left[P_{t} \mid \mathcal{F}_{t-1}^{B}\right]=\bar{P}_{t}^{B}=\bar{P}_{t}^{I N F}\left(1+I_{t}\right)
$$

where $\bar{P}_{t}^{B}$ is the believers' expected price for time $t$ given their information set $\mathcal{F}_{t-1}^{B}$, and $I_{t}$ is the impact of the illusions on the expected prices. $I_{t}$ can depend on many different

\footnotetext{
${ }^{11}$ This means that the illusion is available only at time $t$ and is incorporated into prices at the same time.

${ }^{12}$ We can also assume that the noise traders set their expected prices equal to a mean, which is the same for all market participants, plus a random zero-mean noise.
} 
psychological or economic factors. Moreover, the functional form of this relation can be of many different forms. ${ }^{13}$ In the present simulation, $I_{t}$ is given by:

$$
I_{t}=\psi\left(N_{t-1}+\eta_{t-1}\right) \theta \xi_{t-1}
$$

where $\psi(\cdot)=+1$ or -1 is the desired sign of the illusion, $N_{t-1}$ is the proportion of impatient trades that occurred at time $t-1, \eta_{t-1}$ is an additional proportion of trades that only appears if the market is in a bear period, ${ }^{14} \theta$ is the illusionary trader size, an approximation of the market power that can differ across traders, and $\xi_{t-1}$ represents the quality of the illusion. In principle we consider this quality to be a random variable with uniform distribution on $[0,1]$, but that can also be modeled. We use such randomness because there is no reason to believe that all believers are going to be affected in the same way by different types of news or illusions. One can think of it as an average of the impact of the illusion on the believers.

Knowing the proportion $N_{t}$ of trades at time $t$ (an exogenous variable in the present setting), we can define the composition of the trades in terms of proportions. We assume that the proportion of believers at time $t\left(N_{t}^{B}\right)$ is given by:

$$
N_{t}^{B}=\delta N_{t}
$$

with $0 \leq \delta \leq 1$ such that $0 \leq N_{t}^{B} \leq N_{t}$. Once we know $N_{t}^{B}$ we let the proportion of information traders $\left(N_{t}^{I N F}\right)$ follow a uniform distribution on the interval $\left[0, N_{t}-N_{t}^{B}\right]$. Finally, the proportion of noise traders is simply $N_{t}^{N T}=1-N_{t}^{B}-N_{t}^{I N F}$. Note that in order to obtain $N_{t}^{N T}$ we subtract from 1 and not from $N_{t}$ so that the totality of the market participate in the price formation process. With this structure, even if they are considered as exogenous, the patient traders participate randomly in the price formation process. Hence, this is a flexible structure which allows us to simulate different scenarios like the one in which the market is composed mainly by information traders. For this, we simply need to fix $\alpha \leq N_{t}^{I N F} \leq N_{t}$ and $0 \leq N_{t}^{B} \leq N_{t}-N_{t}^{I N F}$, where $\alpha \geq 0$ represents the

\footnotetext{
${ }^{13}$ This is left for future research. Moreover, we assume that sending an illusion is costless.

${ }^{14}$ With this we are able to capture the leverage effect proposed in Black (1976), i.e. that negative news affect market participants more than positive ones.
} 
minimum proportion of information traders that are present in the market.

When the market is in a bear period, we want to capture the leverage effect observed empirically. We define as bear-believers the traders who behave as information traders in regular times (bull markets) but become believers in bear markets. Their proportion (conditioned on the bear market) $\left(\eta_{t}\right)$ can be defined in many different ways, ${ }^{15}$ for simplicity and to facilitate the exposition, we define it by:

$$
\eta_{t}=N_{t}^{B} N_{t}^{I N F}
$$

i.e., $\eta_{t}$ is the fraction of the proportion of information traders that act as believers in bear markets.

In this simple setup, we do not know anything about traders' demands given their price expectations. Moreover, we do not know what their decision would be (buy, sell or not to trade), according to their preferences for a given price expectation. ${ }^{16}$ Thus, we assume that the actual price is a weighted average of the price expectation of the different kind of traders. ${ }^{17}$ According to these, the price of the asset at time $t$ is:

$$
P_{t}=N_{t}^{I N F}\left(1-N_{t}^{B} D_{t}\right) \bar{P}_{t}^{I N F}+N_{t}^{B}\left(1+N_{t}^{I N F} D_{t}\right) \bar{P}_{t}^{B}+N_{t}^{N T} \varepsilon_{t}
$$

where $D_{t}$ is a dummy variable that takes the value of 1 if we are in a bear market and 0 otherwise. With this specification we do not assume that the illusion is the only noise present in the market. The third term on the right-hand side of equation (4.7) captures this idea and helps the simulations to be more realistic and less controlled.

In order to understand the dynamics of the proposed simulation let us show what happens during the first two periods of trading. At time $t-1$ all kinds of traders fix their strategies. The price at $t$ according to Equation (4.7) has a component driven by the expectations of the information traders $\left(\bar{P}_{t}^{I N F}\right)$, the expectation of the believers $\bar{P}_{t}^{B}$, and the expectation of the noise traders $\left(\varepsilon_{t}\right)$. At time $t$ traders forecast the price for $t+1$. Here one can observe that for the information traders the expected price for $t+1$ is:

\footnotetext{
${ }^{15}$ We can think of defining it as: $\eta_{t}=\pi N_{t}^{I N F}$, where $\pi$ is a uniform random variable on $[0,1]$.

${ }^{16}$ This is an appealing topic for future research.

${ }^{17}$ We can interpret the actual prices as mid-quotes.
} 


$$
\begin{aligned}
\bar{P}_{t+1}^{I N F} & =\frac{1}{n} \sum_{i=1}^{n-1} P_{t-i}+\frac{P_{t}}{n} \\
& =\frac{1}{n} \sum_{i=1}^{n-1} P_{t-i}+\frac{N_{t}^{I N F}\left(1-N_{t}^{B} D_{t}\right) \bar{P}_{t}^{I N F}+N_{t}^{B}\left(1+N_{t}^{I N F} D_{t}\right) \bar{P}_{t}^{B}+N_{t}^{N T} \varepsilon_{t}}{n}
\end{aligned}
$$

Clearly the second term of the sum incorporates the illusion that influences indirectly the information traders. In the case of the believers, as soon as the direct effect of the illusion $\left(I_{t}\right)$ disappears, their expectation converges to the information traders' expectations (see equation (4.3)).

\section{Results}

For the starting values of our simulations we use observed features from the IBM stock: the number of trades and the stock prices over 5-minute intervals. The data was from January 1st 1998 to March 31st 1998. The historical prices are given by the average mid-quote during the time interval. The data we use was taken from the Trades and Quotes (TAQ) dataset, produced by the New York Stock Exchange (NYSE). This data set contains every trade and quote posted on the NYSE, the American Stock Exchange and the NASDAQ National Market System for all securities listed on NYSE. Table 1 presents the descriptive statistics of this data set.

Table 1: Descriptive statistics

\begin{tabular}{l|cc}
\hline \hline & trades & prices \\
\hline Mean & 16.06 & 64.54 \\
Std.Dev. & 7.43 & 3.41 \\
Maximum & 54 & 74.38 \\
Minimum & 0 & 59.38 \\
\hline
\end{tabular}

Descriptive statistics for the number of trades and mid-quote prices (in USD). The number of observations is 4636 and correspond to 765 -minute intervals for 61 trading days. The sample period goes from $01 / 01 / 98$ to $31 / 03 / 98$. 
As stated in Section 4 we assume that the number of trades is not affected by the illusion, what changes is the composition of the different kind of traders. Moreover, we assume that:

- the number of trades follows a Poisson distribution with mean equal to the unconditional mean of the number of trades in 5-minute intervals of IBM (Table 1);

- the expected price of noise traders is assumed to follow a normal distribution with mean and variance equal to the historical mean and variance of the series;

- for the initial composition of the impatient traders, uniform random numbers are generated for each type: information traders, believers and noise traders;

- for the illusionary trader's size $(\theta)$, we chose it to be a uniform random variable in the interval $[0.01,0.15]$, which represents a relative measure of the traders' market cap with respect to the total size of the traders actually intervening in the market;

- the market is bullish.

In order to determine the effect of the illusion, we assume that the illusionary traders expect a random effect of their illusion based on equation (4.4). If they send a positive illusion, they expect that prices go up. However, they also know that the believers will rapidly realize that the illusion is not relevant information and rapidly correct their expectations, forcing the prices to their normal level. Thus, they expect a fall of the prices in the next period. Their strategy in this case is simply to sell after the illusion and buy back the asset when the prices fall into their normal levels. However, it is important to note that given the randomness of the market, the prices might not follow their expectations. In these cases, they do the following:

- If the prices at $t+1$ do not follow their expectations, given the illusion created at time $t$, they do nothing (no action).

- If the prices at $t+1$ follow their expectations, they sell (buy) the asset if they posted a positive (negative) illusion. If the prices at $t+2$ do not fall (rise), they wait for a 
certain period looking for a price that is simply equal to or smaller (bigger) than the price at which they sold (bought) in order to buy (sell) the asset.

Given the above explanations about the way the simulation is driven, we present the results of a simulation based on 1000 replications. The size of the trader in terms of his relative market capitalization is randomly selected from $[0.01,0.15]$ in each replication, i.e., from a small to a large trader.

Figure 1 presents the results of applying the traders strategies described before. We can see that this trading strategy gives a positive payoff as a result of the illusion sent to the market. We see that the expected effect of the illusion is not always achieved, this is the reason why there is a big proportion of zeros (no action).

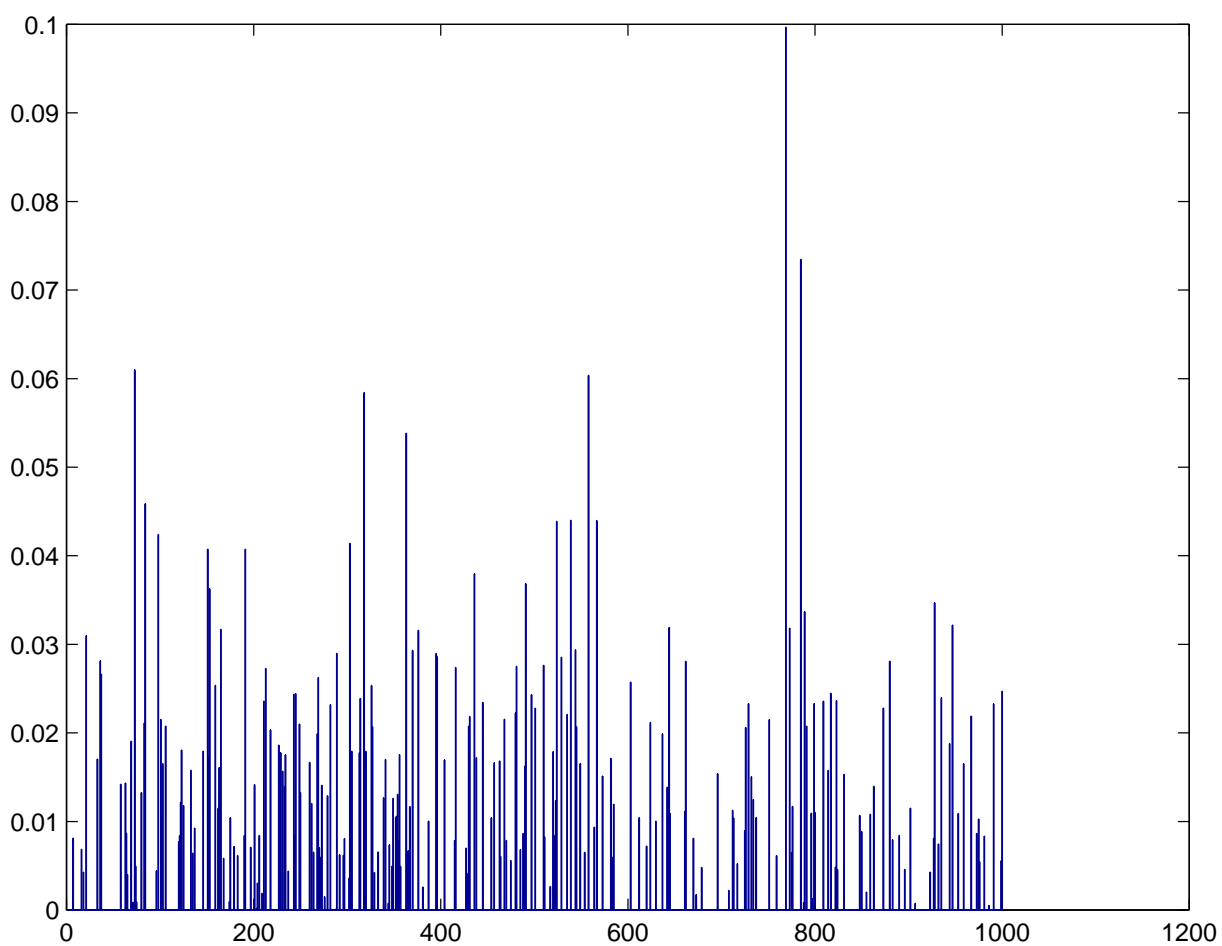

Unit monetary income (vertical axis) resulting of applying the trader's strategy given the illusion sent to the market. The number of simulations is 1000 (horizontal axis).

Figure 1: Traders strategy results

Table 2 presents some statistics of the payoffs obtained sending illusions to the market. One should note that of 1000 illusions, only 241 allow the illusionists to apply their strategies and to obtain a positive payoff. This situation happens because the illusion's impact on the 
prices is given by the believers expected prices, which by assumption are only a proportion of the impatient traders, making their influence very limited.

Table 2: Traders strategy results: some statistics

\begin{tabular}{l|ccccccc}
\hline \hline Period & max & min & mean & std & sum & action & no action \\
\hline \multirow{2}{*}{ Bull } & 0,0997 & 0,0000 & 0,0040 & 0,0096 & 3,9634 & 241 & 759 \\
\hline \hline
\end{tabular}

This table present some results of the traders strategies given the illusions sent to the market. The results are presented in monetary units for a trade of a single share. "Action" refers to the number of times the expected traders' illusion has the desired impact on the market prices. "No action" refers to the number of times when the trader's illusion did not produce the desired effect and so the trader did not do anything.

Table 3 shows some statistics about the proportion of the different kind of traders that result as a consequence of illusions sent to the market. It also shows some statistics about the price expectations of the different traders. Looking at that table, one notices that the maximum proportion of impatient traders (traders that submit market orders) represents one quarter of the total market traders. From this group the information traders represent the majority. We can see that the impact of the illusion is very small, with a maximum of $8.99 \%$ and a minimum of zero (no impact).

Table 3: Illusions impact

\begin{tabular}{l|cccc}
\hline \hline Period: Bull & max & min & mean & std \\
\hline & & & & \\
Impatient traders (\%) & 0.2367 & 0.0233 & 0.1098 & 0.0256 \\
Information traders(\%) & 0.1733 & 0.0003 & 0.0542 & 0.0279 \\
Believers (\%) & 0.0899 & 0.0000 & 0.0015 & 0.0075 \\
Noise traders (\%) & 0.9993 & 0.8062 & 0.9444 & 0.0281 \\
Expected price information traders & 60.0155 & 59.9468 & 59.9778 & 0.0214 \\
Expected price believers & 61.1454 & 58.5995 & 59.9787 & 0.0815 \\
Expected price noise traders & 60.0445 & 59.9177 & 59.9777 & 0.0236 \\
Realized prices & 60.0701 & 59.8519 & 59.9777 & 0.0236 \\
\hline \hline
\end{tabular}

This table present some results of the impact of the illusions on the proportion of believers and on the realized prices.

By assumption the largest group of traders are the noise traders, which includes the proportion of patient traders who place their limit orders exogenously and randomly. Another 
interesting feature to observe is that the expected prices of the different type of traders are not very different. These results are coherent with the price movements observed in stock markets in which the prices cannot vary more than a certain level without triggering a market halt.

\section{Conclusions}

In this paper we introduce the concept of illusionary finance. Our analysis focus on how the illusions can be created and disseminated in stock markets. We expose in a market microstructure context, how a trader can profit from other agents psychological biases, taking advantage of polysemous signals and time pressure. Illusionary finance proves to be possible since agents cannot make fully-rational decisions all the time. Illusionary traders take advantage from the believers which can be either information traders or noise traders.

Illusionary traders are not necessary for markets to be operative (as information and noise traders) but they exist. Our contribution is thus to introduce the concept of illusionary finance, which is a realistic way to integrate the functioning of stock markets with psychological aspects of the traders.

An interesting conclusion derived from our simulation is, that even though information traders are skeptical about the illusions at time $t$, they end up indirectly including the illusion in their forecast of the next period after the illusion was created, showing once again the power the illusions have in financial markets.

In our study our intention was to show that financial illusions may exist in financial markets even it is difficult to detect them. A possible extension of our ideas is to develop a theoretical model of illusions in which the existence and survival of the illusionary trader can be shown. Another extension could be to develop a model which considers the impact of illusions on the patient traders, i.e. in the traders that submit limit orders. 


\section{References}

Agnoli, F. (1991): "Development of Judgmental Heuristics and Logical Reasoning: Training Counteracts the Representativeness Heuristic," Cognitive Development, 6(2), 195217.

Agnoli, F., And D. KRAntz (1989): "Suppressing Natural Heuristics by Formal Instruction: The Case of the Conjunction Fallacy," Cognitive Psychology, 21(4), 515-550.

Barberis, N., A. Shleifer, And R. Vishny (1998): "A Model of Investor Sentiment," Journal of Financial Economics, forthcoming, 49(3).

Black, F. (1976): "Studies of price volatility changes," Procedings of the 1976 meetings of the Business and Economics Statistics section, American Stititical association.

Black, F. (1986): "Noise," Journal of Finance, 41(3), 529-543.

Bodenhausen, G. (1990): "Stereotypes as Judgmental Heuristics: Evidence of Circadian Variations and Discrimination," Psychological Science, 1(5), 319-322.

CobB, V. (1999): How to Really Fool Yourself : Illusions for All Your Senses. Wiley; New Ed edition.

Coval, J., D. Hirshleifer, And T. Shumway (2002): "Can Individual Investors Beat the Market?," Harvard NOM Working Paper No. 02-45.

Daniel, K., D. Hirshleifer, and A. Subrahmanyam (1998): "Investor Psychology and security Market Under- and Overreactions," The Journal of Finance, LIII(6), $1839-1885$.

De Long, J., A. Shleifer, L. Summers, and R. Waldman (1990): "Noise Trader Risk in Financial Markets," Journal of Political Economy, 98(4), 703-738.

DeBondt, W. F. M., And R. H. Thaler (1985): "Does the Stock Market Overreact?," Journal of Finance, 40(3), 793-808.

Dretske, F. (1981): Knowledge and the Flow of Information. MIT press, Cambridge.

FAMA, E. F. (1970): "Efficient Capital Markets: A Review of Theory and Empirical Work," Journal of Finance, 25(2), 383-417. 
Finucane, M., A. A., P. Slovic, and S. Johnson (2000): "The Affect Heuristic in Judgements of Risk and Benefits," Journal of Behavioral Desicion Making, 13(1), $1-17$.

Glosten, L. R. (1994): "Is the Electronic Open Limit Order Book Inevitable?," The Journal of Finance, 49(4), 1127-1161.

Harris, L. (2003): Trading and Exchanges. Oxford University Press, New York.

Hirshleifer, D., ANd G. Luo (2001): "On the survival of overconfident traders in a competitive securities market," Journal of Financial Markets, (4), 73-84.

Isen, A., T. Nygren, and G. Ashby (1988): "Influence of Positive Affect on the Subjective Utility of Gains and Losses: It is Just Not Worth the Risk," Journal of Personality and Social Psychology, 55(5), 710-717.

Kahneman, D. (1991): "The Endowment Effect, Loss Aversion, and Status Quo Bias: Anomalies," Journal of Economic Perspectives, 5(1), 193-206.

(2000a): "Evaluation by Moments: Past and Future," in Choices, Values and Frames, ed. by D. Kahneman, and A. Tversky. Cambridge University Press, New York.

(2000b): "Experienced Utility and Objective Happiness: A Moment-Based Approach," in Choices, Values and Frames, ed. by D. Kahneman, and A. Tversky. Cambridge University Press, New York.

- (2003): "Maps fo Bounded Rationality: Psychology of Behavioral Economics," The American Economic Review, pp. 1449-1475.

Kahneman, D., and S. Frederick (2002): "Representativeness Revisited: Attribute Substitution in Intuitive Judgement," in Heuristics and Biases: the Psychology of Intuitive Thought, ed. by T. Gilovich, D. Griffin, and D. Kahneman, pp. 49-81. Cambridge University Press, Cambridge.

Kahneman, D., And A. Tversky (1979): "Prospect Theory: An Analysis of Decision Under Risk," Econometrica, 47, 263-291. 
Kahneman, D., P. Wakker, and R. Sarin (1997): "Back to Bentham? Explorations to Experienced Utility," Quarterly Journal of Economics, 112(2), 375-405.

Mellers, B. (2000): "Choice and the Relative Pleasure of the Consequences," Psychological Bulletin, 126.

Nisbett, R., D. Krantz, C. Jepson, and Z. Kunda (1983): "The Use of Statistical Heuristics in Everyday Inductive Reasoning," Psychological Review, 90(4), 339-363.

Saussure, F. (1967): Cours de Linguistique Générale. Paris.

Shafir, E., And R. LeBoeuf (2002): "Rationality," Annual Review of Psychology, 53(1), $419-517$.

Shleifer, A., And R. Vishny (1997): "The Limits to Arbitrage," Journal of Finance, $52(1), 35-55$.

Simon, H. (1957): "A Behavioral Model of Rational Choice," In Models of Man.

Stanovich, K., And R. West (2000): "Individual Differences in Reasoning: Implications for the Rationality Debate," Behavioral and Brain Sciences, 23(5), 645-665.

Thaler, R. (1993): Advances in Behavioral Finance. Russell Sage Foundation, New York.

Tversky, A., And D. Kahneman (1974): "Judgement under Uncertainty: Heuristics and Biases," Science, 185(4157), 1124-1131.

(1992): "Advances in Prospect Theory: Cumulative Representation of Uncertainty," Journal of Risk and Uncertainty, 5(4), 297-323. 
Département des Sciences Économiques de l'Université catholique de Louvain

Institut de Recherches Économiques et Sociales

Place Montesquieu, 3

1348 Louvain-la-Neuve, Belgique 